\title{
Cecília Meireles, uma lírica no auge do modernismo
}

\author{
Ana Amélia Neubern Batista dos Reis*
}

\section{Resumo}

O presente artigo tem como objetivo refletir sobre aspectos da obra Cecília Meireles e sobre o diálogo que ela estabeleceu com a Índia. Também, pretende-se mostrar como as relações da autora com a tradição hindu contribuíram para a formação do pensamento ceciliano expresso em sua obra. Essa relação, tanto com a tradição indiana como com a modernidade da Índia representadas pelas figuras de Gandhi e Tagore -, pode apontar para outras bases de formação do movimento modernista brasileiro, o qual, até nossos dias, é fundamentalmente embasado nas ideias de Mário e Oswald de Andrade. Visando a ampliar a mirada para o modernismo brasileiro, abordando-o de forma múltipla, apresenta-se um ponto de inflexão para pensarmos no modernismo de forma mais alargada e diversa. Tal ponto de inflexão utilizado neste texto para desenvolver as reflexões propostas é o curso de literatura Técnica e Crítica Literárias, que Cecília Meireles ministrou em 1937, não publicado até o momento, por meio do qual é possível perceber como o pensamento ceciliano dialoga com as tradições antigas e estabelece relações descomplicadas com essas tradições (especialmente com a da Índia). Portanto, a obra de Cecília Meireles pode representar uma grande contribuição para repensar o modernismo no Brasil.

Palavras-chave: Cecília Meireles. Índia. Modernismo Brasileiro.

* Doutora em Estudos Literários pela UFMG (2019). Professora temporária do Instituto Federal do Norte de Minas - campus Pirapora. Orcid: 0000-0002-3704-1469. 


\title{
Cecília Meireles: a lyric poet in the era of high modernism
}

\begin{abstract}
This article aims to reflect on aspects of Cecília Meireles' work and the dialogue she established with India. Also, it intends to show how the author's relations with the Hindu tradition contributed to the formation of Cecilian thought expressed in her work. This relationship, both with Indian tradition and with Indian modernity - represented by the figures of Gandhi and Tagore - may point to other bases for the formation of the Brazilian modernist movement, which, to this day, is fundamentally based on the ideas of Mário and Oswald de Andrade. Aiming to broaden the gaze on Brazilian modernism, approaching it in a multiple way, it presents a turning point for thinking about modernism in a broader and more diverse way. Such inflection point used in this text to develop the proposed reflections is the literature course "Literary Technique and Criticism", which Cecília Meireles taught in 1937, not published so far, through which it is possible to see how Cecilia's thought dialogues with the ancient traditions and establishes uncomplicated relationships with these traditions (especially with that of India). Therefore, the work of Cecília Meireles can represent a great contribution to rethink modernism in Brazil.
\end{abstract} Keywords: Cecília Meireles. India. Brazillian modernism.

Recebido em: 15/10/2021 // Aceito em: 22/12/2021. 
Em janeiro de 1953, Cecília Meireles aterrissa em solo indiano, a convite do governo da recém-independente Índia. O motivo do convite foi a participação da escritora, como representante do Brasil, no seminário Ghandian Outlook and Techniques, dedicado a pensar as contribuições que as ideias de Gandhi poderiam trazer aos diversos países do mundo, a fim de se trilhar um caminho de paz mundial. Além disso, na ocasião, a poeta recebeu o título de doutora honoris causa da Universidade de Delhi. A viagem, que teve duração de dois meses, pode ser considerada a coroação de um diálogo duradouro que Cecília estabeleceu com a Índia, especialmente, com a filosofia hindu.

Assim, a partir dessa viagem, a autora publica, anos depois, Poemas escritos na Índia, livro no qual a filosofia e mitologia indianas figuram de forma patente em cada poema, mas tal presença aparece, desde o início da produção literária da autora. Em seu livro de estreia, Espectros, já se mostrava, de forma seminal, as ressonâncias da Índia na obra de Cecília. Os três livros inaugurais da autora, a saber, Espectros, Nunca mais... e Poema dos poemas foram excluídos de sua obra poética, publicada em 1958, pela própria poeta. Dilip Loundo afirma que esses textos iniciais refletem, "até certo ponto, as leituras introdutórias que fez do lirismo místico de Rabindranath Tagore." (LOUNDO, 2007, p. 132). Em certo sentido, havia ali algo embrionário ainda não incorporado de forma decisiva em sua obra. Nos livros posteriores, a presença da Índia se torna parte orgânica do corpo literário que foi gerado por Cecília Meireles. De acordo com Antonio Carlos Secchin:

O Oriente, todavia, e, mais particularmente a Índia ocupam um lugar central na geografia poética ceciliana, porque, para além de seu espaço físico, simbolizam uma sabedoria de vida e uma lição de cultura que se 
disseminam, mais ou menos explicitamente, em quase todos os livros da autora. É oportuno recordar que já o segundo poema do seu primeiro livro (Espectros, de 1919), um soneto intitulado "Brâmane", descreve, no epílogo, a figura de um hindu "Que contempla, extasiado, o firmamento". E um dos últimos poemas de Cecília, escrito a menos de seis meses de sua morte, se chama "Breve elegia ao Pandit Nehru". Nas duas extremidades da existência, a Índia. (SECCHIN, 2010, p. 134).

A constatação de que a Índia se espraia pela obra de Cecília, podendo ser reconhecida do início ao fim de sua produção literária, deve-se ao fato de Secchin ser um profícuo pesquisador da obra de Cecília, ${ }^{1}$ ainda que não um pesquisador especificamente voltado para as relações da autora com a Índia. O diálogo que Cecília Meireles entabula com a Índia tem tamanha importância para a abordagem de sua obra que, sem considerá-lo, os escritos da autora podem ficar reservados, pela crítica, a um lugar ainda mais peculiar do que já se apresenta. É sabido que sua obra representa um desafio para a crítica literária, justamente porque não conversou diretamente com a base consagrada do modernismo que tinha, nas ideias de Mário e Oswald de Andrade, seu pilar. Manuel Bandeira, em 1946, no intento de apresentar a obra da autora (da qual Bandeira era, assumidamente, leitor e admirador), ${ }^{2}$ a define como "uma voz distinta entre os nossos poetas" (BANDEIRA, 1997, p. 142143). O poeta e crítico Miguel Sanches Neto, também no afã de apresentar e refletir sobre a obra ceciliana, em importante ensaio de abertura da edição da obra completa da autora, em 2001, comemorando os cem anos do nascimento da escritora,

\footnotetext{
1 Antonio Carlos Secchin organizou a obra poética de Cecília Meireles, em 2001, e trouxe à público as três obras iniciais de Cecília que estavam fora de circulação há muitas décadas.

2 Manuel Bandeira dedica à Cecília o poema Improviso, no qual constrói antíteses na tentativa de apreender o ser da poeta, como no verso "libérrima e exata" (BANDEIRA, 2007, p. 194).
} 
arrisca uma solução: ele reconhece que Cecília se une a uma "ala moderna, sem ser exteriormente modernista [...]" (SANCHES NETO, 2001, p. XXIV).

Leila V. B. Gouvêa, uma das maiores estudiosas de Cecília Meireles, que fez contribuições inestimáveis para a crítica acadêmica ceciliana e para a divulgação de sua obra, também situa o pensamento de Cecília em um lugar não propriamente encaixado em seu momento. Segundo Leila Gouvêa:

Desde já, é possível considerar que um dos diferenciais mais flagrantes da lírica de Cecília Meireles face à poesia brasileira de seu tempo localizava-se no reduzido aproveitamento, em seu universo de temas e motivos, da matéria do cotidiano e do banal, da cidade e do povo, do humorístico e do prosaico - ou seja, do concreto e do empírico.

[...]

Menos do que nas soluções formais, como o recurso ao verso livre - do qual lançou mão, de modo muito peculiar, em grande número de poemas desde a década de 1920, residirá na rarefação de muitas das bandeiras temáticas de nossos poetas modernistas, especialmente a do aproveitamento da matéria prosaica do cotidiano, o desgarramento dessa lírica do contexto estético de sua contemporaneidade. (GOUVÊA, 2008, p. 66).

O que percebemos por essas análises da crítica literária é que há um desajuste, digamos, entre a obra ceciliana e o modernismo brasileiro. Porém, há uma questão que não foi levantada entre os críticos mencionados: essa "voz distinta" não será, também, a voz de um modernismo que não se encaixa adequadamente na vertente mais estudada e, até mesmo, mais veiculada historicamente, de afirmação identitária, de compromisso histórico, sociológico e ideológico? Segundo a visão modernista dominante, de fato, a poética ceciliana pode ser dissonante. Entretanto, é possível apontar que a tensão central 
existente não é a voz distinta dessa literatura e, sim, o movimento literário reduzido a uma vertente predominante, limitado em sua capacidade de apreensão das diversas expressões de seu momento estético. Assim, com o advento forçado da passagem do tempo, temos agora uma distância histórica que nos possibilita revisitar o momento do modernismo no Brasil e mesmo lançar questões sobre, por exemplo, a "modernidade" do modernismo brasileiro. Portanto, podemos pensar qual foi o som central do modernismo que, de certa forma, abafou a ressonância de outras vozes. Ou seja, podemos deslocar um pouco a lupa e olhar para o modo de apresentação do modernismo como faltante. E, não, necessariamente, para a obra de Cecília, e outras tantas, como dissonante.

Dito isso, é importante enfatizar: a perspectiva pela qual os argumentos deste artigo são abordados não é a de diminuir ou mesmo de procurar fissuras no pensamento predominante modernista, aquele encabeçado por Mário de Andrade. O que se pretende é oferecer a visão de uma autora que refletiu sobre seu momento estético e sobre literatura de forma distinta daquela que se apresenta, até nossos dias, como, talvez, a única maneira de pensar sobre tal momento histórico-estético. Assim, visa-se propor uma via de entrada para se ler o modernismo que não seja por meio, apenas, da antropofagia, do pensamento da ruptura com a tradição ou do nacional.

Nesse sentido, o escritor Luís Augusto Fischer é categórico e até contundente. Na entrevista que ele concedeu a João Pombo Barile, em 2015, Fischer analisa que, em 1942, tanto Mário de Andrade, quanto o autor Vianna Moog fizeram um balanço do modernismo após 20 anos da semana de 1922. Cada um trazia uma visão distinta sobre a literatura brasileira. Enquanto Mário de Andrade $^{3}$ apostava na: 
[...] ideia de uma literatura brasileira como unidade, a cara, a identidade da literatura brasileira estava clara e definida - a literatura brasileira era o modernismo (o paulistano, centrado na famosa semana, protagonizada por ele mesmo), ou aquilo que o modernismo tinha, segundo ele, proporcionado. (FISCHER, 2015).

Vianna Moog, ${ }^{4}$ por sua vez, defendia a tese de que não existia algo que se poderia chamar de "literatura brasileira". $\mathrm{O}$ que ele apontou foram "sete ilhas, formando um arquipélago que é o Brasil. As sete ilhas seriam o Norte, a Bahia, o Nordeste, Minas e seu entorno, São Paulo, o Sul com centro no Rio Grande do Sul, e o Distrito Federal, o Rio, a antiga corte [...]" (FISCHER, 2015). As distintas visões expostas naquele ano de 1942, representam para Fischer um marco importante, pois:

[...] estava-se decidindo o futuro não da literatura brasileira em si, mas o modo como a literatura brasileira seria vista, a partir de então. A visão unitarista, subordinada a certa perspectiva de vanguarda (nacionalista), de experimentação e tal, apresentada pelo Mário, viria a triunfar, na universidade, nas escolas, nos manuais, nos vestibulares, finalmente no modo como todo mundo pensa na literatura brasileira. (FISCHER, 2015).

E Fischer continua apontando como essa visão tornou-se hegemônica e até hoje tem sido aceita dessa forma:

É como se a versão da história do modernismo contada pelos intelectuais paulistanos tivesse se tornado hegemônica...

Mas preste atenção, bem atenção: não quero com isso dizer que um tinha razão e outro não. Meu ponto é que ali, em 1942, dá para flagrar bem um momento de virada da visão que o Brasil fazia de si. E bem para quem, como eu, tem grande resistência ao triunfo da

4 A conferência proferida por Clodomir Vianna Moog, em 1942, recebeu o nome de Um arquipélago cultural e teve abrangente relevância à época. Mais tarde, foi publicada em livro. Cf. Moog (1983). 
visada modernista sobre o conjunto do Brasil, sobre o conjunto da literatura brasileira, esse momento deveria ser mais estudado e mais retomado. Ali estava ainda em jogo, em disputa, a interpretação do país; dali por diante, com a maré montante dos estudos brasileiros concebidos na USP, muitos deles a partir do mesmo Mário, o "modernismocentrismo" triunfou, impondo uma visão que me parece muito restritiva, muito limitada historicamente, e muito cruel. Dali por diante, escritor que queira ser bem visto tem que rezar pela cartilha marioandradina, porque do contrário vai ser considerado antigo, pré-modernista, qualquer coisa dessas. Uma pena, mas este é o processo. (FISCHER, 2015).

Levando-se em consideração o neologismo cunhado pelo pesquisador, "modernismocentrismo", podemos perceber a tensão que existe entre a proposta modernista - alinhada às ideias de Mário, que buscava, sem dúvida, uma atitude decolonial, revolucionária e libertária (inclusive dos padrões estéticos preestabelecidos) - e a forma impositiva com que esse modernismo se estruturou na sociedade. Inclusive, seguindo o pensamento de Fischer, a leitura da época modernista direciona a análise e o entendimento, também, da literatura brasileira pregressa, considerando-a como menor, antiquada. É como se o modernismo tivesse se tornado a régua de medida literária, a lupa por meio da qual olhamos para a literatura brasileira. Advindos daí, há termos cunhados como pré-modernismo, por exemplo. É também em função do pensamento modernista predominante que houve tentativas, por parte da crítica, de afinar a obra ceciliana a movimentos pregressos, como o simbolismo. Não há qualquer desajuste em colocar tal obra em diálogo com outros movimentos e tradições, uma vez que a própria autora fez isso explicitamente. Porém, o que fica subentendido é uma certa não modernidade na obra de Cecília. Aí reside o ponto de 
inflexão deste estudo. Defende-se que a obra de Cecília Meireles é absolutamente moderna e modernista (numa visão ampliada do modernismo brasileiro) e o ponto de diálogo moderno de sua obra é aquele que ela estabeleceu principalmente com a tradição e com a modernidade indianas.

No artigo Repensando o nacional à margem da "Civilização": R. Tagore, o folclore de Bengala e a construção da modernidade indiana, Marcus Wolff (2014) aborda as diferenças do nacionalismo no contexto indiano, dialogando com o nacionalismo modernista brasileiro. $\mathrm{O}$ autor lê as investidas feitas pela família Tagore e, mais especificamente, por Rabindranath Tagore, no folclore de Bengala, como o cerne da construção de um pensamento nacional indiano que resistiu ao pensamento dominante ocidental (e, no caso da Índia, resistiu ao domínio imperial em sentido literal). Em outro artigo, Wolff (2017) se dedica a mostrar que a visão que Cecília Meireles elaborou sobre o poeta Rabindranath Tagore inaugura uma irmandade pós-colonial entre a Índia e a América Latina. Seria importante, talvez, refletir sobre como o interesse e as pesquisas de Cecília acerca do folclore brasileiro também poderiam apontar, assim como ressalta Wolff com relação à Índia, para uma construção distinta da modernidade e do nacional. Para além de Tagore, a valorização, na obra de Cecília, do pensamento de Gandhi e da independência da Índia como um marco revolucionário para pensar uma nova sociedade, é de suma importância para deslocar as ideias sobre o nacional para além daquele que foi veiculado por meio do viés europeu.

Dessa forma, considerando o método limitado de recepção da diversidade ao tratar daquele momento histórico-estético, podemos perceber afinidades com o método aprendido, no 
Brasil, pela colônia, ou seja, se alguém não fala a língua da colônia (ou do modernismo central), ou é excluído, ou deve aprender essa língua. É importante reiterar que estamos tratando da forma como o modernismo brasileiro é analisado e não de uma análise sobre a produção literária modernista dominante, que, sem dúvida alguma, foi brilhante.

Se analisarmos de forma geral a perspectiva mariandradina e a que Oswald de Andrade trouxe para a literatura, poderíamos dizer que aquela teve um cunho mais nacionalista e esta um caráter, talvez, mais cosmopolita. Ainda assim, o próprio Oswald de Andrade, num rompante, vai dizer:

A sra. Cecília Meireles é uma espécie de Morro de Santo Antônio, que atravanca o livre tráfego da poesia. Com sua celebridade madura, continua a fazer o mesmo verso arrumadinho, neutro e bem cantado, com fitinhas, ou melhor, com fitinhos e bordados. Sem dizer nada, sem transmitir nada. Mesmo sem sentir nada. (ANDRADE, 2007, p. 553-554).

Ao afirmar que Cecília atravanca o livre tráfego da poesia, é possível perguntar-se: qual poesia? Em outro momento, Oswald se posiciona contra a premiação de Cecília Meireles pelo livro $\mathbf{O}$ Aeronauta argumentando o seguinte:

Uma das condições do prêmio era ser dado por unanimidade de votos. E unanimidade só mesmo a humana simpatia do velho romancista do Nordeste poderia obter. Eu comecei votando no Lampião de Rachel de Queiroz. Houve uma cabala enorme a favor de sra. Cecília Meirelles, pois ainda há gente que aprecie os artifícios dessa grande contemporânea de Fradique Mendes que ainda acredita na Índia dos rajás, ignorando a Índia do comunismo, e Rachel não teve os sufrágios da forma que eu desejava. Passei 
então a dar ganho de causa aos Cangaceiros que reputo o melhor livro. (ANDRADE, 2007, p. 665-666, (grifo nosso). ${ }^{5}$

A ironia na mensagem de Oswald é clara. "Ainda há gente que aprecie", ou seja, os remanescentes do passado ainda apreciam esse tipo de poesia. E o julgamento de valor se completa com a menção ao poeta fictício Fradique Mendes, criado pelos portugueses Eça de Queiroz e Antero de Quental, entre outros, durante os anos de 1868-1869. De fato, analisando a obra ceciliana (que inclusive, já foi amplamente colocada em diálogo com os poetas portugueses), não há qualquer problema em situá-la como "contemporânea" de Fradique Mendes (estaria ela em boa companhia). Mais uma vez, percebe-se que a relação de Cecília com a tradição foi explícita e descomplicada. No entanto, a ironia de Oswald ao dizer "a grande contemporânea de Fradique Mendes", não está se referindo propriamente à poesia de Cecília, mas, sim, ao "passadismo" de suas escolhas poéticas. Além disso, há uma pincelada de crítica na questão do vínculo com Portugal, que, sabe-se, pelo menos num primeiro momento modernista, foi relegado a segundo plano em detrimento da cultura francesa que impulsionou as ideias dos modernistas no Brasil. 6

Sobre a crítica à crença na "Índia dos rajás", não seria nem possível afirmar que Cecília Meireles fizesse poesia oriental; ela não copiava seus pares indianos, os rajás. Ela nutria-se do modo de pensar deles, de seu entendimento sobre poesia, e o reverberava na sua língua, no seu próprio modo de fazer e entender literatura.

\footnotetext{
5 Ao final, quem recebeu o prêmio foi José Lins do Rego, com Cangaceiros.

6 Sobre o assunto, há o artigo Presença da literatura francesa no modernismo brasileiro, de Tânia Franco Carvalhal. A autora traz um curioso fato sobre Mário de Andrade: talvez ele tenha sido um dos únicos artistas da primeira hora do modernismo que não visitou, presencialmente, a França. Mário nunca saiu de seu país. E, ainda assim, ele pode ser considerado o mais profícuo leitor e mediador daquela cultura para o Brasil.
} 
Cecília foi uma aguçada observadora da vida e do mundo, uma dedicada e detalhista recolhedora das miudezas do cotidiano, dos cristais do cotidiano; havia assuntos da ordem do dia em sua obra, mas havia, também, um tratamento diferenciado da linguagem. De acordo com a própria Cecília:

[...] é evidente que, desde 1920, com o chamado modernismo, o intêresse voltou-se para a expressão, livre da forma. O movimento dessa alternativa é conhecido: o excesso de intêresse pela forma pode chegar a inutilizar a expressão e vice-versa. Todos sabem que um poema perfeito é o que apresenta forma e expressão, num ajustamento exato. Não sei se as condições atuais do mundo permitem esse equilíbrio, porque serão raros os poetas tão em estado de vivência puramente poética, livres do atordoamento do tempo, que consigam fazer do grito, música, - isto é, que criem poesia como se formam os cristais. Mas creio que todos padecem, se são poetas. Porque, afinal, se sente que o grito é o grito; e a poesia já é o grito (com tôda a sua fôrça) mas transfigurado. (MEIRELES, 1958, p. LXXVII-LXXVIII).

O grito de Cecília passa por uma transfiguração que compreende a eternidade na aparente efemeridade e pode dar a qualquer lagartixa branca ares de deusa, como no poema Comunicação:

\section{COMUNICAÇÃO}

Pequena lagartixa branca, ó noiva brusca dos ladrilhos! sobe à minha mesa, descansa debruça-te em meus calmos livros.

Ouve comigo a voz dos poetas que agora não dizem mais nada, - e diziam coisas tão belas! ó ídolo de cinza e prata! 
Ó breve deusa de silêncio que na face da noite corres como a dor pelo pensamento, - e sozinha miras e foges.

Pequena lagartixa - vinda para quê? - pousa em mim teus olhos Quero contemplar tua vida, a repetição dos teus mortos.

Como os poetas que já cantaram, e que já ninguém mais escuta, eu sou também a sombra vaga de alguma interminável música.

Para em meu coração deserto! Deixa que te ame, ó alheia, ó esquiva... Sobre a torrente do universo, nas pontes frágeis da poesia.

(MEIRELES, 2001a, p. 635-636, v.1).

Comunicação é uma ponte. O poema faz ouvir a voz dos poetas que agora não dizem mais nada e nos faz escutar a vaga música, ${ }^{7}$ que ninguém mais escuta. Cecília nos apresenta no poema uma voz poética que contempla. Contempla uma pequena (e, comumente, tratada como insignificante) vida, como a de uma lagartixa branca. E essa insignificante vida desata o questionamento sobre o sentido primevo (ou último) da existência: "Pequena lagartixa - vinda / para quê? - pousa em mim teus olhos / Quero contemplar tua vida, / a repetição dos teus mortos [...]". Nota-se que esta pergunta fundamental, "vinda / para quê?", repete-se em outros poemas da autora. Em Elegia sobre a morte de Gandhi: "Que queria este homem?" I "Por que veio ao mundo este homem?" (MEIRELES, 1958, p. 976). Esse aspecto de questionar sobre o sentido da vida e

7 Vale notar, nas estrofes “eu sou também a sombra vaga / de alguma interminável música [...]”, a referência ao título do livro Vaga Música, que fora publicado sete anos antes de Retrato natural. 
atribuir um sentido a todas as formas viventes, aparecerá em inúmeros poemas ao longo da obra ceciliana, assim como no belo Elegia a uma pequena borboleta: "Como chegavas do casulo, / — inacabada seda viva — / tuas antenas — fios soltos / da trama de que eras tecida, / e teus olhos, dois grãos da noite /de onde o teu mistério surgia [...]" (MEIRELES, 2001a, p. 608 , v. 1). Em Comunicação, entretanto, além de a lagartixa figurar como existência animal, ela aparece como um reflexo da voz poética que, por vezes, pode ser considerada, assim como a lagartixa, alheia e esquiva, uma vez que o eu-lírico é "também a sombra vaga / de alguma interminável música [...]". Quer dizer, a voz poética está ressoando a música de outrora que já não é mais cantada, mas que, nesse momento poético, no encontro com a brusca noiva dos ladrilhos, pode ser resgatada e, somente em forma de linguagem, cantada; somente em forma de poesia, também, a lagartixa pode ser amada. O pequeno animal rastejante, a breve deusa de silêncio, é também uma ponte entre a efemeridade da sua existência e a eternidade de sua fixação em poesia. "A Beleza é uma felicidade imortal" (MEIRELES, 1999b, p. 267, v. 2), disse Cecília ao final da crônica Um dia em Calcutá.... E a busca pela Beleza, que parece ter sido um atributo veemente na poesia antiga, é também um atributo valorizado na poesia de Cecília.

Pode ser que, para um poeta como Oswald, uma lagartixa branca represente o que ele chama de "fitinhos e bordados", num verso "arrumadinho". Mas não foi apenas o autor de Memórias sentimentais de João Miramar que julgou a obra de Cecília com a curta régua do modernismo da época. Como um exemplo da afirmação de Fischer acerca do momento decisivo sobre como a literatura brasileira seria vista a partir da década de 1940, há 
um artigo crítico do poeta Mário Faustino, datado de 1957, sobre Cecília Meireles. O poeta a avalia dessa forma:

Cecília Meireles pode não ser o mais fértil dos poetas brasileiros de importância: é, sem dúvida, o mais prolixo.

$[\ldots]$

Cecília é, de longe, o melhor poeta do seu sexo na língua portuguesa na América Latina. De todas as "poetisas" que já lemos, apenas Safo, Emily Dickinson, Marianne Moore e Edith Sitwell são-lhe superiores.

[...]

D. Cecília publica demais. O melhor que se poderia fazer em prol de sua glória seria preservar o Romanceiro completo, fazer uma antologia de uns cinquenta grandes poemas (Mar absoluto seria o maior contribuinte) e queimar o resto. Mas não nos esqueçamos de perguntar: quantos poetas em nossa língua já assinaram cinquenta grandes poemas? A outra pergunta que nos ocorre: por que d. Cecília publica tanto? - cabe aos psicanalistas responder.

$[\ldots]$

Cecília Meireles, em matéria de versificação técnica, tem só um rival sério na poesia contemporânea da língua: Manuel Bandeira (se nós estivéssemos nos referindo a vidrilhos, lantejoulas, esmaltes e camafeus, teríamos dito, talvez, Guilherme de Almeida ou Olegário Mariano, porém, até na fabricação desses inúteis objetos Cecília os bate longe). (FAUSTINO, 2003, p. 181-182).

E, após transcrever trechos soltos de poemas como: "Palavra. Pequeno rumor / entre a eternidade e o momento", o poeta do admirável $\mathbf{O}$ homem e a sua hora, avalia o seguinte:

Essas coisas, em seu melhor, são apenas cacoetes femininos, iguais aos de Bette Davis ou aos de Morineau. Em seu pior, são vulgaridades, efeitos baratos, bric$\grave{a}$-brac indigno de quem escreveu, em Romanceiro da Inconfidência e em Mar absoluto, alguns dos maiores versos da língua.

$[\ldots]$ 
O pior defeito das mulheres-poetas é pensarem - como, aliás, muito homem também pensa - que palavras bonitas, relembrando ao leitor coisas bonitas, "palavras que fazem suspirar", é pensarem que essas palavras, nelas mesmas, já são poesia. Pode ser que sejam, mas pode ser que não sejam: geralmente não são. Quem quiser conhecer o extremo oposto, isto é, poesia só poesia mesmo, sem nada a ver com as tais "coisas bonitas", leia Blake e leia Donne. (FAUSTINO, 2003, p. 183).

Ao dizer que preservar o Romanceiro completo seria o melhor que se poderia fazer em prol da glória da poeta Cecília, Faustino nos deixa a sugestão do viés nacionalista valorizado à época. Realmente, ao considerarmos o conjunto da obra de Cecília Meireles, o Romanceiro da Inconfidência pode ser considerada a obra que mais dialoga, em temática, com os postulados modernistas, ainda que os versos sejam "arrumadinhos" à maneira ceciliana. É possível, também, fragilizar as bases da crítica de Faustino, uma vez que a decisão sobre a quantidade que se publica ou mesmo o que deve ou não deve falar um poeta, não parece ser matéria de preocupação do crítico, a não ser que esse crítico esteja vinculado a uma vertente estética que comporte apenas determinadas manifestações, como parece ter sido o caso. Faustino elenca e transcreve dois ou três poemas da "grande Cecília", mas fica evidente que a medida estética por meio da qual ele avalia a poesia da autora não contempla a tentativa de compreensão da obra e das escolhas estéticas de Cecília. Não se trata de não haver qualquer base estética para sua análise, a questão é que a base é restrita, não importa qual seja a obra. E aí reside a crueldade sobre a qual fala Fischer. Novamente, os "bordados e fitinhos" voltam a incomodar, dessa vez metaforizados em lantejoulas, vidrilhos, esmaltes (?) e camafeus. 
Infelizmente, não se pode deixar de notar que a questão de gênero atravessa vários momentos do texto de Faustino: "O pior defeito das mulheres-poetas", "cacoetes femininos", "melhor poeta do seu sexo", isso quer dizer que com os poetas do outro sexo ela não é comparável? (apesar de, sim, em matéria de versificação técnica ela "poder" ser comparada a Manuel Bandeira). Além dos comentários restritivos que as concepções do autor transferem para a obra ceciliana, vale ressaltar a deselegância de linguagem (que não são dignas do autor do belo Vida toda linguagem), com a qual Faustino aborda essa poética. Em outro momento de seu texto, Faustino diz que valeria queimar ou jogar "na cesta, não nas livrarias" a grande parte dos poemas da autora e oferece conselhos (críticos?) dessa natureza: "E nunca mais publicar coisas como 'Ciclo do sabiá' [...]" (FAUSTINO, 2003, p. 185).

Portanto, a exposição de Faustino pode ser a representação de uma ideia que outros críticos também veicularam em meados do século 20, mostrando a dificuldade para dialogar com a obra de Cecília Meireles. É importante ressaltar que tal dificuldade de diálogo não é surpreendente para um homem inserido no contexto da década de 1950. Surpreendente seria o contrário. Percebe-se, mais uma vez, um método colonial bem apreendido: quem cita as regras do que é ou não poesia, do que se deve ou não publicar são os homens, brancos. A questão problemática que é ressaltada neste estudo é a atual manutenção de traços dessa crítica com relação à obra da mulher Cecília Meireles. Em um artigo de 2018, Lirismo engajado, Valéria Lamego pontua vários aspectos da "combatente" Cecília nos anos 30 e ressalta perspectivas de engajamento da obra ceciliana no drama social de sua época. Assim, Lamego ressalta: 
Podemos atribuir ao machismo da crítica - que até a década de 1980 foi basicamente representada por autores homens e brancos, para ficarmos no clichê do momento - a leitura enviesada de Cecília. Mas não podemos aceitar que, nos dias atuais, essa leitura se perpetue em textos canhestros, no quais o autor se rejubila por não conhecer sua obra, mergulhando em um simplório estigma para desenhar um falso e preguiçoso retrato da poeta. Ou poetisa? Pergunta-se hoje. (LAMEGO, 2018, p. 16).

De toda forma, mesmo tendo sido alvo de críticas enviesadas, é preciso marcar que o diálogo entre Cecília Meireles e Mário de Andrade foi de fluidez e de amizade; não uma amizade íntima como aquela que a poeta nutriu, por exemplo, com o escritor português Armando Côrtes-Rodrigues ou com as escritoras Lúcia Machado de Almeida e Henriqueta Lisboa. Mário escreveu pouco sobre Cecília, ${ }^{8}$ porém, quando o fez, foram críticas elogiosas, reconhecendo a importância e profundidade de sua obra. Ambos os escritores mantiveram uma correspondência breve, mas interessante para pensar as questões da época e, também, para reconhecer a fraternidade entre Cecília e Mário. Ele, com seu caro humor, menciona em uma das cartas: "Mas porque esses homens imbecis não ceciliameirelizam a vida!" (MEIRELES, 1996, p. 304). Reitera-se, assim, que o escopo dos argumentos apresentados neste estudo não são personalidades modernistas, tampouco, a produção literária da época. O que se pretende é o levantamento de reflexões que podem contribuir para os estudos literários numa direção de ampliação de horizontes com relação à abordagem crítica do modernismo em nossos dias. ${ }^{9}$

\footnotetext{
8 Há dois breves artigos de análise de poemas de Cecília, por Mário de Andrade, são eles: Cecília e a Poesia e Viagem, constantes da obra $\mathbf{O}$ empalhador de passarinho.

9 Leila Gouvêa ressalta uma análise de Cecília Meireles sobre Mário e Oswald, pontuando diferenças no ideário estético de ambos os escritores. Cecília aponta uma liberdade maior na visada de Mário, "mais preocupada em debater problemas
} 
No que se refere à recepção da própria Cecília com relação a esse olhar para sua obra como dissonante, é possível dizer, especialmente, por meio de sua correspondência, que ela era cônscia do lugar de sua obra e a produzia dessa maneira, intencionalmente. Há a passagem, em uma de suas cartas enviadas à escritora mineira Lúcia Machado de Almeida, na qual Cecília conta à amiga sobre uma dança indiana que assistiu na embaixada da Índia, no Rio de Janeiro, em 2 de março de 1949:

[...] a dança era descritiva e mística representando a paixão espiritual de uma princesa pelo deus Krishna. [...] E o mais engraçado é que perto dessas velhíssimas danças... o modernismo ocidental fica de um ridículo sem nome. Todos os modernismos em todas as artes. Aquilo é velho e eterno como o mundo e o homem. Reduzido a esquemas, a infantilidades, a sonho dadaísmo, futurismo, surrealismo... Havia muito o que dizer, entrando até pelo existencialismo e o epifanismo. Ficará para um dia. (MEIRELES,.., 1949).

Percebemos, nesse trecho, uma contraposição não apenas entre o modernismo como escola literária, mas como uma ideia ocidental. O termo ocidental ao ser colocado como adjetivo de modernismo, marca bem o referencial do argumento. Há margem, nessa declaração, para filtrarmos a diferenciação que a própria autora atribuía aos pensamentos ocidentais e orientais - os esquemas, infantilidades e sonhos representados pelos "-ismos" que marcam a estética ocidental numa determinada época e o existencialismo e o epifanismo representando o pensamento oriental, de ordem metafísica. 
Além disso, retomando os argumentos de Faustino e analisando as possíveis reverberações desse pensamento na obra de Cecília, com relação a ser uma mulher escritora em meio a um ambiente centralmente masculino, nos textos e cartas analisadas, não há passagens que tratem do tema de maneira estanque; porém, a forma como Cecília manteve seu pensamento estético que abarcava as reflexões sobre o universal, em contraposição à onda nacionalista dominante, já pode ser considerada um ponto de enfrentamento dessa realidade. Além disso, o próprio fato de ter seguido na carreira como escritora é também um modo de se posicionar e abrir espaço para futuras gerações de mulheres escritoras. ${ }^{10}$ Em uma de suas missivas, a própria Cecília nomeia a correspondência entre ela, Lúcia e Henriqueta, de "Confraria da Sereia", poetizando que "não será uma Nossa Ordem Social ou Política, mas uma Nossa Ordem Lírica e Mística [...]" (MEIRELES, , 1945); o que nos leva a ler a "Ordem Social e Política" como a ordem "masculina". Tal comentário nos permite delinear a construção intelectual de Cecília Meireles, com base na qual - apesar de dialogar com um contexto em que as mulheres não estavam inseridas (ou muito pouco) na produção intelectual e literária da época - a autora trilha um caminho de total dedicação à intelectualidade e à literatura, mas não sem os percalços das atribuições diárias "femininas" que cabiam às mulheres de meados do século XX. ${ }^{11}$

\footnotetext{
10 Cf. Silva (2021). Nessa tese, o autor aprofunda as questões políticas tangentes à vida e à obra de Cecília Meireles, dialogando com o feminismo da época.

11 Essa dedicação exclusiva à escrita e à intelectualidade não eximiu Cecília de desempenhar as funções "femininas" da época. A escritora criou três filhas, cuidou da casa e das outras tarefas que cabiam às mulheres da época. Em sua correspondência, especialmente, aquela trocada com Lúcia Machado de Almeida, há inúmeras passagens que tratam das dificuldades de levar a lida da vida diária conjugada com a escrita. Há também, trocas de receitas e de amenidades domésticas.
} 


\section{0 curso Técnica e Crítica Literárias em diálogo com o modernismo brasileiro}

Com o intuito de compreendermos um pouco melhor o pensamento ceciliano acerca da literatura, o curso intitulado Técnica e Crítica Literárias que a professora Cecília ministrou em 1937, na Universidade do Distrito Federal, pode ser considerado um marco para sedimentar as ideias literárias que são reconhecidas por meio de seus escritos.

As aulas, que estão disponíveis na Fundação Casa de Rui Barbosa, iniciam-se em 28 de junho de 1937 e terminam em 29 de novembro do mesmo ano. Elas foram estenografadas pela aluna Vera Teixeira, sem revisão da professora. Pela leitura do conjunto, nota-se que há aulas que não foram registradas pela aluna; de toda forma, a maior parte delas está transcrita e vale ressaltar que, ainda que o documento não tenha sido revisado por Cecília, pelo seu conteúdo, percebe-se ampla coerência com as propostas da escritora. Ainda, há dois detalhes que possibilitam inferir que as aulas foram anotadas com rigor: o primeiro é que quando as aulas se referem à filosofia e à mitologia indianas, como os Vedas, o Mahabharata e o Ramayana, há vacilações na ortografia dos nomes próprios. Ora a aluna escreve corretamente, ora com algum erro. O conteúdo, no entanto, é exato. Isso demonstra um caminho da aprendiz ao acercar-se, provavelmente, de um assunto desconhecido, como devia ser a tradição antiga hindu em 1937 (e ainda o é, em certa medida).

Afora os pequenos erros ortográficos, todo o conteúdo do curso é estritamente objetivo e coerente com os estudos que se têm sobre os assuntos abordados, trazendo, inclusive, em algumas aulas, a bibliografia dos livros de base. Assim, 
considera-se essas notas como válidas e como uma valiosa transmissão do conhecimento de Cecília Meireles, que, pelo que se verifica, com apenas 36 anos, cultivava um saber sólido sobre as grandes tradições filosóficas, religiosas e literárias do mundo, conforme se percebe ao longo das aulas. Leila Gouvêa tece alguns comentários gerais sobre curso apresentado por Cecília e qualifica, acertadamente, a aluna Vera Teixeira como “presciente”, uma vez que, em 1937, Cecília já trilhava a carreira de professora e jornalista, mas ainda não havia se estabelecido como a poeta que viria a ser reconhecida após o ano de 1938, quando recebeu o prêmio da Academia Brasileira de Letras e, com ele, a notoriedade que iria receber ao longo da vida.

Para abordar o tema da técnica e da crítica literárias, Cecília vai visitar os mais remotos tempos do "homem primitivo" e de seus costumes, mostrando, muitas vezes, similaridades entre o homem desse longínquo passado e o homem moderno. Nas primeiras aulas, Cecília apresenta como o homem primitivo se identificava com o clã ou com o grupo e não havia a noção de indivíduo que hoje, até certo ponto, nos identifica como sujeitos. ${ }^{12}$

As aulas vão enfocar principalmente os textos sagrados das grandes tradições do mundo. Cecília aborda a tradição hebraica, com análises de livros bíblicos, o Talmud judeu; a tradição chinesa com enfoque nas obras de Confúcio e Lao Tsé; a tradição japonesa (de forma breve), e se aprofunda, amplamente, na base das escrituras sagradas da Índia, analisando textos do Rig Veda, Atharva Veda, Upanishads, Mahabharata e Ramayana (os três primeiros filosóficos e os dois últimos, mitológicos). As aulas aprofundam as explicações sobre os textos formadores

\footnotetext{
12 Das leituras de base, ela menciona, na aula de 28 de junho (MEIRELES, 1937), Oswald Spengler (El hombre y la tecnica e Decadencia do Ocidente), Levy Bruhl (L'âme primitive, Les fonctions mentales de la societé inferieure, La mentalité primitive), Henri Bergson (L'energie spirituelle) e Henry Delacroix (Le langage et la pensée).
} 
das sociedades tradicionais e, gradativamente, vão abordando a questão dos mitos e textos até chegarà literatura. São contemplados os mitos heroicos, sagrados, os contos maravilhosos e populares, fábulas e outras formas de textos que já apresentam elementos literários até chegar à concepção de literatura que se tem no tempo moderno. Para que possamos compreender um pouco da concepção de literatura que Cecília Meireles cultivava, serão apontados alguns elementos importantes para que seja possível entabular um diálogo entre as ideias de Cecília Meireles e alguns de seus pares modernistas.

Conforme dito, por meio das aulas percebe-se a visão de Cecília sobre a intrincada relação entre o homem primitivo $^{13}$ e o moderno. Vale realçar que Cecília aceita uma diferença entre a mentalidade do homem primitivo e entende que houve evolução em relação ao moderno. Ainda assim, ela traz, na aula de 2 julho, alguns exemplos em que se verifica a ancestralidade dos seres em meio às relações atuais do século XX: "Naturalmente, o homem primitivo - que aliás ainda hoje se encontra em qualquer reunião de feira - quando quer domar um cavalo ou um burro tem interjeições tão adequadas que animal e homem se entendem perfeitamente." (MEIRELES, 1937). ${ }^{14}$

E essa percepção do encontro entre o primitivo e o moderno também é expressa por meio de objetos simbólicos que remontam a ideias e a sentimentos tradicionais, como descrito na aula de 21 de julho:

\footnotetext{
13 Ainda que este termo, "primitivo", seja discutível na atualidade, vou manter, em alguns momentos, sua utilização, pois foi como Cecília, à época, nomeou as sociedades ancestrais.

14 Tal temática pode ser reconhecida no poema Banho dos Búfalos, de Poemas escritos na Índia: "Na água viscosa, cheia de fôlhas, / com franjas róseas da madrugada, / entram meninos levando búfalos. / Búfalos negros, curvos e mansos, / - oh, movimentos seculares! - / odres de leite, sonho e silêncio. / Cheia de fôlhas, a água viscosa / brilha em seus flancos e no torcido / esculturado lírio dos chifres. / Sobem e descem pela água densa, / finos e esbeltos, por entre as flôres, / estes meninos quase inumanos, / com ar de jovens guias de cegos, / - oh, leves formas seculares - / tão desprendidos de pêso e tempo!" (MEIRELES, 1961, p. 12).
} 
O homem primitivo com seus totens diante de casa ou nos caminhos que a ela conduziam tem seus vestígios na bandeira que hoje hasteamos nos edifícios públicos, lembrando ao povo o sentimento de unidade. Há entre os dois fatos uma ligação que, por leve que seja, constitui a conservação de um sentimento primitivo no homem moderno. (MEIRELES, 1937).

Por esse comentário, captamos uma possível base para o sentimento do nacional. A bandeira funcionaria como um totem que une em torno de si o clã, o grupo ou a nação. Se confrontarmos esse comentário com o verso "Sem bandeiras. Sem uniformes. Só alma, no meio de um mundo desmoronado [...]", do poema Elegia sobre a morte de Gandhi (MEIRELES, 1958, p. 976), veremos que, na concepção ceciliana, a ideia de unidade não está fundamentada em qualquer objeto que se justifique no exterior dos seres. Na obra de Cecília Meireles, é possível reconhecer que a ideia de unidade está baseada em uma relação metafísica do ser humano físico com seu correspondente sutil, e não em uma relação objetiva e referencial. E esse é um ponto de tensão entre a obra de Cecília Meireles e o modernismo, ainda que os modernistas também não tenham apostado na representação da bandeira para pensar a unidade nacional. Aparece - em lugar desse totem verde e amarelo - o índio, o homem do povo, o interior do Brasil, como lugar de manutenção da unidade cultural e nacional. De toda forma, o elemento da unificação é exteriorizado, o que diverge, até certo ponto, do pensamento ceciliano, que inclui a perspectiva do universal.

Ainda estabelecendo diálogo entre o primitivo e o moderno, a professora Cecília elenca alguns exemplos de personalidades que foram adquirindo características míticas. Ela menciona D. Sebastião e o movimento chamado "sebastianismo", 
que, segundo Cecília se mantinha "vivíssimo" em Portugal. Como afirma na aula de aula de 21 de jullho, os portugueses não esperavam pela volta, de fato, do rei ("Esperar por D. Sebastião, / Quer venha ou não!"), ${ }^{15}$ "mas sim a volta daquele espírito de aventura que venha a animar o povo português [...]" (MEIRELES, 1937). Também Hitler aparece nas reflexões de Cecília sobre formação do sentimento de nação por meio de um comportamento que pode remontar às "velhas tradições" (na aula de 21 julho):"Recorrendo ao presente vemos que os próprios chefes europeus de hoje dariam elementos admiráveis para mitos. Hitler, querendo incentivar o sentimento conjugal de seu povo, não faz mais que avivar-lhes as velhas tradições." (MEIRELES, 1937). E vai ser justamente esse "sentimento conjugal de seu povo", que remonta à unidade do clã, uma das sementes que irá, poucos anos depois, fazer brotar uma grande guerra.

E dessa forma segue a professora estabelecendo vínculos entre a tradição e a atualidade (da época) que vão revelando a amplitude da concepção de Cecília sobre os seres humanos, o mundo e suas manifestações. Há também uma atribuição do caráter mítico a algumas personalidades por parte de Cecília. As biografias que Cecília escreveu sobre Gandhi e sobre Rui Barbosa mostram a valorização dessas personalidades como figuras exemplares. Ambas as biografias contemplam um caráter pedagógico com relação a Gandhi e Rui Barbosa como homens heroicos. Por essa postura ceciliana, ressaltam-se também as possíveis tensões de ideias com relação àqueles afinados com o

15 Menção ao poema Liberdade, de Fernando Pessoa, autor que explorou o "mito" desse rei de Portugal no seu primeiro livro, Mensagem. Cf. PESSOA (2005), p. 188-189. 
modernismo que viam na figura do herói alguém que precisava ser combatido (especialmente com relação ao controverso Rui Barbosa). ${ }^{16}$

No que tange à literatura como uma manifestação humana, Cecília vai perscrutar os mais antigos textos de mitologia como um campo implicado na literatura (e isso é relevante na obra literária que Cecília construiu). O mito é apresentado no curso Técnica e Crítica Literárias de forma bastante complexa, levandose em consideração as diversas linhagens de pensamento sobre o mito: aquela que atrela o mito a acontecimentos históricos; aquela que atribui uma origem única aos mitos, a saber, a Índia; aquela que concebe o mito como uma alegoria do sol e cria uma forma única de interpretação para os mitos em torno da metáfora solar da criação; ou, ainda, a vertente que tem o complexo de Édipo como base para os mitos, que teriam sua fonte na "tragédia interior do homem", visão que foi combatida pela compreensão da volonté de puissance, a vontade de poder, veiculadas pela corrente de pensadores posteriores a Freud, como Alfred Adler.

Cecília, todavia, nos apresenta uma visão distinta dessas apontadas. Ainda que a Índia esteja presente em quase todas as aulas ministradas, ou como menção comparativa, ou como fonte de análise, ela explicita não ser partidária da visão de que a fonte para os mitos e contos seria unicamente a Índia; apesar de considerar que a Índia, sendo uma das tradições mais antigas sobre a qual se tem registro, contribuiu grandemente para a formação do imaginário mítico de inúmeras regiões do mundo.

Ao longo de todo o curso, que se estende trazendo a concepção do aparecimento da literatura a partir dos textos tradicionais, a autora vai apontar, por exemplo (na aula de 5 novembro), a base estética indiana, chamada rasa, que, segundo a professora:

16 As biografias são Rui e Gandhi: um herói desarmado. 
Esse estudo do "Rasa" vem a ser a base da crítica indú [sic] dos velhos tempos que tem sofrido modificações, é verdade - mas que perdura quando se trata de julgar uma obra de arte. Ela nos dá a chave da compreensão da belesa [sic], desde os velhos tempos da Índia, e nos dá a medida dessa estética num povo preocupado com a filosofia mais do que com a religião. No estudo do que se chama a religião do oriente o que encontramos é uma filosofia, é a fusão de todas as explicações do Universo, a distinção entre o eu e o não eu, o que vale dizer, entre o mundo objetivo e o mundo subjetivo e as relações entre um e outro. Isso é pura filosofia e é isso a base da religião indú [sic]. Trata, antes de tudo, de uma discussão filosófica. Vamos ter ocasião de ver, pela leitura de alguns Upanishads, que eram ensinamentos transmitidos de mestre a discípulo em forma oral e em caráter secreto, que eles revelam a distinção existente entre a religião dos hindus e a dos hebreus. Embora não estejamos aqui preocupados com discussões teológicas, a observação é necessária porque nos encontramos diante de um novo caminho e como esses ensinamentos vão perdurar através de toda a literatura indú [sic], é útil conhecermos a maneira de se comportar o pensamento indú [sic] em face dos problemas da vida. Enquanto a preocupação dos hebreus é consolidar a sociedade, organizá-la em bases sólidas e dar-lhes um Deus que sirva de união entre os homens, os indús [sic] têm a preocupação é de distinguir a divindade e seus atributos, classificá-la e mostrar a identidade dessa divindade com o eu. (MEIRELES, 1937).

Assim, por meio da abordagem sobre rasa, tomamos conhecimento da abrangência do pensamento ceciliano sobre literatura e é possível dizer que a segurança com que Cecília explorou formas tradicionais da literatura (como o "romanceiro", os sonetos, a poesia lírica) pode ser atribuída a esse vasto conhecimento e a uma abertura para ler as tradições. O que não quer dizer que ela não tenha experimentado versos livres à sua maneira e flertado com o surrealismo, por exemplo, em 
suas crônicas, principalmente. Esse modo ceciliano de receber a história literária do mundo, tentar conhecê-la e buscar criar a partir dela, pode ser considerado um aspecto de vanguarda, moderno, por excelência. Essa forma de ver ressoar no cotidiano corriqueiro elementos antigos e perceber que a literatura tem uma base que, em dado momento, não foi literária é importante para refletirmos sobre a própria existência da literatura, assim como, de forma conclusiva, expõe a professora Cecília (na aula de 26 novembro):

Como fizemos, a princípio, um estudo de literatura tradicional e um de literatura sagrada, já pudemos ver que temas houve que passaram de uma dessas formas para outras. Assim vimos temas que eram antes do domínio popular e passaram para o domínio da literatura escrita, constituindo os velhos livros que são a fixação de episódios que foram úteis à vida do grupo, da clan [sic] ou da nação e que foram conservados como motivo de ligação para esse grupo ou nação. Vimos temas que se generalizaram tornando-se universais, vimos como essa generalização acarreta, às vezes, modificações, e encontramos como fonte preciosa de todos os temas a magia, nas culturas primitivas. Essa magia que verificamos entre judeus, indús [sic], chineses e verificaríamos ainda entre os japoneses e em todos os outros povos do oriente si [sic] tivéssemos tido tempo de estudar todos os seus livros sagrados, perdeu sua aparência de magia para assumir uma aparência literária. (MEIRELES, 1937).

Após a apreciação de alguns trechos que nos levam a conhecer mais profundamente a bagagem de formação do pensamento ceciliano, podemos enfatizar que esse pensamento pode ser mais estudado com vistas a uma ampliação do olhar que lançamos para o modernismo brasileiro. Esse estudo se propõe a ser um início de conversa, não um encerramento com respostas. Há muito o que ser pensado, pesquisado e escrito sobre o assunto, 
como tem sido feito nas últimas décadas. Penso que uma gama de escritores e escritoras modernistas podem se tornar mais relevantes por meio desses estudos. Além disso, há um grande valor na postura de Cecília Meireles de buscar conhecer o outro, profundamente, se possível. E essa tentativa de apreensão do outro com vistas a formarmos uma sociedade mais humana tem sido uma prerrogativa de nossos dias atuais. Assim, a leitura e os estudos da obra de Cecília, além de contribuírem para o campo da crítica literária, também podem levar cada sujeito a tomar ciência de um desconhecido: o si mesmo.

\section{Referências}

ANDRADE, Oswald. Voto a descoberto. In: Telefonema. São Paulo: Globo, 2007. p. 553-554.

ANDRADE, Mário de. Cecília e a poesia. In: ANDRADE, Mário de. O empalhador de passarinho. São Paulo: Livraria Martins Editora, 1972. p. 71-75.

ANDRADE, Mário de. Viagem. In: ANDRADE, Mário de. O empalhador de passarinho. São Paulo: Livraria Martins Editora, 1972. p. 161-164.

ANDRADE. Mário. O movimento modernista: Conferência lida no Salão de Conferências da Biblioteca dos Ministérios das Relações Exteriores do Brasil, no dia 30 de abril de 1942. Rio de Janeiro: Edição da Casa do Estudante do Brasil, 1942. Disponível em: http://www.bibliotecadigital.unicamp.br/ document $/$ code=64439\&opt=1. Acesso em: 02 out. 2021 .

BANDEIRA, Manuel. Apresentação da poesia brasileira. Rio de Janeiro: Ediouro, 1997. p. 142-144. 
BANDEIRA, Manuel. Estrela da vida inteira. São Paulo: Círculo do Livro, 2007.

CARVALHAL, Tânia Franco. Presença da literatura francesa no modernismo brasileiro. In: CHAVES, Flávio Loureiro et al. Aspectos do Modernismo Brasileiro. Porto Alegre: UFRGS, 1970. p. 149-187.

CORRESPONDÊNCIA de Cecília Meireles a Henriqueta Lisboa (1931-1963). Acervo de Escritores Mineiros (AEM/UFMG).

CORRESPONDÊNCIA de Cecília Meireles a Lúcia Machado de Almeida (1944-1962). Acervo de Escritores Mineiros (AEM/ UFMG).

FAUSTINO, Mário. O livro por dentro. In: FAUSTINO, Mário. De Anchieta aos concretos. São Paulo: Companhia das Letras, 2003. p. 181-185.

FISCHER, Luis Augusto. De frente para o mar, de costas pro Brasil. [Entrevista cedida a] João Pombo Barile. Suplemento literário de Minas Gerais, Belo Horizonte, mar./abr. 2015.

GOUVÊA, Leila V. B. Pensamento e lirismo puro na poesia de Cecília Meireles. São Paulo: EDUSP, 2008.

LAMEGO, Valéria. Lirismo engajado. Revista Quatro, Cinco, Um, p. 16-17, 16 maio 2018. Disponível em: https://www. quatrocincoum.com.br/br/resenhas/educacao,poesia,literatura/ lirismo-engajado. Acesso em: 20 set. 2021.

LOUNDO, Dilip. Cecília Meireles e a Índia: viagem e meditação poética. In: GOUVÊA, Leila V. B. (org.). Ensaios sobre Cecília Meireles. São Paulo: Humanitas, 2007. p. 129-176.

MEIRELES, Cecília. Cecília e Mário. Rio de Janeiro: Nova Fronteira, 1996.

MEIRELES, Meireles. Crônicas de viagem. Rio de Janeiro: Nova Fronteira, 1999b, v.2. 
MEIRELES, Cecília. Third Session: Madame Cecília Meireles. $I n$ : Ghandian Outlook and Techniques. Verbatim Report of the Proceedings of the Seminar on the Contribution of Gandhian Outlook and Techniques. Ministry of Education Government of India, 1953. Disponível em: https://archive.org/details/in.ernet. dli.2015.499877/page/n3. Acesso em: 30 ago. 2020.

MEIRELES, Cecília. Gandhi: um herói desarmado. In: LIMA, Alceu Amoroso et. al. Grandes Vocações: Quatro Apóstolos Modernos. São Paulo: Donato Editora, s.d. p. 245-328.

MEIRELES, Cecília. Obra Poética. Rio de Janeiro: José Aguilar, 1958.

MEIRELES, Cecília. Poesia completa. SECCHIN, Antonio Carlos (org.). Rio de Janeiro: Nova Fronteira, 2001a. v. 1.

MEIRELES, Cecília. Poesia completa. SECCHIN, Antonio Carlos (org.). Rio de Janeiro: Nova Fronteira, 2001b. v. 2.

MEIRELES, Cecília. Poemas escritos na Índia. Rio de Janeiro: Livraria São José, 1961.

MEIRELES, Cecília. Rui: pequena história de uma grande vida. São Paulo: Gráfica Revista dos Tribunais, 1949. (Edição comemorativa do centenário de Rui Barbosa).

MEIRELES, Cecília. Técnica e Crítica literárias (curso estenografado por Vera Teixeira). Fundação Casa de Rui Barbosa - Fundo CM, 1937.

MELLO, Ana Maria Lisboa de; UTEZA, Francis. Oriente e Ocidente na poesia de Cecília Meireles. Porto Alegre: Libretos, 2006.

MOOG, Vianna. Uma interpretação da literatura brasileira: um arquipélago cultural. Rio de Janeiro: Edições Antares, 1983. OLIVEIRA, Ana Maria Domingues de. Estudo crítico da bibliografia sobre Cecília Meireles. São Paulo: Humanitas; FFLCH; USP, 2001. 
OLIVEIRA, Gisele Pereira de. Cecília Meireles e a Índia. Das provisórias arquiteturas ao "êxtase longo de ilusão nenhuma". Tese (Doutorado em Letras) - Faculdade de Letras, Universidade Estadual Paulista, Assis, 2014.

PESSOA, Fernando. Obra poética. Rio de Janeiro: Editora Nova Aguilar, 2005.

SANCHES NETO, Miguel. Cecília Meireles e o tempo inteiriço. In: MEIRELES, Cecília. Poesia Completa. Rio de Janeiro: Nova Fronteira, 2001, p. 21-59.

SECCHIN, Antonio Carlos. Cecília Meireles e os Poemas escritos na Índia. In: SECCHIN, Antonio Carlos. Memórias de um leitor de poesia. Rio de Janeiro: Topbooks, 2010. p. 133140.

SILVA, Denilson de Cássio. Cecília Meireles e o humanismo cívico: Palavras e práticas de um ideário político (Brasil Sudeste, 1915-1964). Tese (Doutorado em História) - Universidade Federal de Minas Gerais, Faculdade de Filosofia e Ciências Humanas (FAFICH), Programa de Pós-graduação em História, Belo Horizonte, 2021.

WOLFF, Marcus Straubel. O Tagore de Cecília e outros Tagores. Contexto, Vitória, n. 31, 2017.

WOLFF, Marcus Straubel. Repensando o nacional à margem da "Civilização": R. Tagore, o folclore de Bengala e a construção da modernidade indiana. Música \& Cultura, Salvador, v. 9, p. 1-21-21, 2014. Disponível em: https://edisciplinas.usp.br/ pluginfile.php/348693/mod_resource/content/0/285-336-1-PBMarcus\%20Wolff-modernidade\%20indiana.pdf. Acesso em: 20 jul. 2021. 